\title{
The Science of Scale for Violence Prevention: A New Agenda for Family Strengthening in Low- and Middle-Income Countries
}

\section{OPEN ACCESS}

Edited by:

Andres M. Rubiano,

El Bosque University, Colombia

Reviewed by:

Laura Nabors,

University of Cincinnati, United States Katalin Dr. Papp,

University of Debrecen, Hungary

*Correspondence:

Yulia Shenderovich

y.shenderovich@gmail.com;

yulia.shenderovich@spi.ox.ac.uk

tThese authors share first authorship

Specialty section:

This article was submitted to

Children and Health,

a section of the journal

Frontiers in Public Health

Received: 02 September 2020 Accepted: 18 February 2021 Published: 19 March 2021

Citation:

Shenderovich Y, Lachman JM

Ward CL, Wessels I, Gardner F, Tomlinson $M$, Oliver $D$, Janowski $R$, Martin M, Okop K, Sacolo-Gwebu H,

Ngcobo LL, Fang Z, Alampay L,

Baban A, Baumann AA, de

Barros RB, Bojo S, Butchart A,

Dippenaar W, Exavery A, Fang $X$, Ferdinandi I, Foran HM, Heinrichs N, Hutchings J, Kisyombe D, Massetti G, Mazak J, Mbuyi H, Singh P, Polsky K,

Rakotomalala S, Raleva M, Savo R and Cluver L (2021) The Science of Scale for Violence Prevention: A New

Agenda for Family Strengthening in

Low- and Middle-Income Countries.

Front. Public Health 9:581440.

doi: 10.3389/fpubh.2021.581440
Yulia Shenderovich ${ }^{1,2 *+}$, Jamie M. Lachman ${ }^{1,3+}$, Catherine L. Ward ${ }^{4}$, Inge Wessels ${ }^{1,4}$, Frances Gardner ${ }^{1}$, Mark Tomlinson ${ }^{5,6}$, Daniel Oliver ${ }^{7}$, Roselinde Janowski ${ }^{4}$, Mackenzie Martin ${ }^{1}$, Kufre Okop ${ }^{4}$, Hlengiwe Sacolo-Gwebu ${ }^{4}$, Lindokuhle L. Ngcobo ${ }^{8}$, Zuyi Fang ${ }^{1}$, Liane Alampay ${ }^{9}$, Adriana Baban ${ }^{10}$, Ana A. Baumann ${ }^{11}$, Regina Benevides de Barros ${ }^{12}$, Samuel Bojo ${ }^{13}$, Alexander Butchart ${ }^{14}$, Wilmi Dippenaar ${ }^{15}$, Amon Exavery ${ }^{16}$, Xiangming Fang ${ }^{17}$, Ida Ferdinandi ${ }^{18}$, Heather M. Foran ${ }^{19}$, Nina Heinrichs ${ }^{20}$, Judy Hutchings ${ }^{21}$, Daisy Kisyombe ${ }^{22}$, Greta Massetti ${ }^{23}$, Jaromir Mazak ${ }^{24,25}$, Henry Mbuyi ${ }^{26}$, Pratibha Singh ${ }^{27}$, Kenneth Polsky ${ }^{7}$, Sabine Rakotomalala ${ }^{28}$, Marija Raleva ${ }^{29}$, Richard Savo ${ }^{30}$ and Lucie Cluver ${ }^{1,31 \dagger}$

${ }^{1}$ Department of Social Policy and Intervention, University of Oxford, Oxford, United Kingdom, ${ }^{2}$ Centre for the Development and Evaluation of Complex Interventions for Public Health Improvement (DECIPHer), School of Social Sciences, Cardiff University, Cardiff, United Kingdom, ${ }^{3}$ MRC/CSO Social and Public Health Sciences Unit, University of Glasgow, Glasgow, United Kingdom, ${ }^{4}$ Department of Psychology, University of Cape Town, Cape Town, South Africa, ${ }^{5}$ Department of Global Health, Institute for Life Course Health Research, Stellenbosch University, Stellenbosch, South Africa, ${ }^{6}$ School of Nursing and Midwifery, Queens University, Belfast, United Kingdom, ${ }^{7}$ Catholic Relief Services, Baltimore, MD, United States, ${ }^{8}$ Clowns Without Borders South Africa, Cape Town, South Africa, ${ }^{9}$ Department of Psychology, Ateneo de Manila University, Quezon City, Philippines, ${ }^{10}$ Department of Psychology, Babes-Bolyai University, Cluj-Napoca, Romania, ${ }^{11}$ Brown School of Social Work, Washington University in St. Louis, St. Louis, MO, United States, ${ }^{12}$ Division of Global HIV and TB, Centers for Disease Control and Prevention, Atlanta, GA, United States, ${ }^{13}$ Agency for Research and Development Initiative, Juba, South Sudan, ${ }^{14}$ Department of Injury and Violence Prevention, World Health Organization, Geneva, Switzerland, ${ }^{15}$ The Seven Passes Initiative, Wilderness, South Africa, ${ }^{16}$ Pact Tanzania, Dar es Salaam, Tanzania, ${ }^{17}$ School of Public Health, Georgia State University, Atlanta, GA, United States, ${ }^{18}$ UNICEF Montenegro, Podgorica, Montenegro, ${ }^{19}$ Institute for Psychology, Universitat Klagenfurt, Klagenfurt, Austria, ${ }^{20}$ Department of Psychology, University of Bremen, Bremen, Germany, ${ }^{21}$ School of Psychology, Bangor University, Bangor, United Kingdom, ${ }^{22}$ Pact Eswatini, Mbabane, Eswatini, ${ }^{23}$ Division of Violence Prevention, Centers for Disease Control and Prevention, Atlanta, GA, United States, ${ }^{24}$ Schola Empirica, Prague, Czechia, ${ }^{25}$ Faculty of Arts, Charles University, Prague, Czechia, ${ }^{26}$ Catholic Relief Services DRC, Gombe, Democratic Republic of Congo, ${ }^{27}$ Emmanuel Hospital Association, New Delhi, India, ${ }^{28}$ Global Partnership to End Violence Against Children, World Health Organization, Geneva, Switzerland, ${ }^{29}$ Department of Child and Adolescent Psychiatry, St. Cyril and Methodius University Skopje, Skopje, Macedonia, ${ }^{30}$ Catholic Relief Services Zimbabwe, Harare, Zimbabwe, ${ }^{31}$ Department of Psychiatry and Mental Health, University of Cape Town, Cape Town, South Africa

Ending all violence against children by 2030 is a core part of Sustainable Development Goals 5 and 16. A number of promising violence reduction strategies have been identified in research studies. However, we lack an understanding of the implementation and impact of these programs in respect to their delivery at a large scale or within existing service systems, particularly in low- and middle-income countries (LMICs). We advocate for greater collaboration between researchers, policymakers, donors, governments, non-governmental organizations, and program managers and staff to study how violence prevention programs operate on a large scale. We describe a new initiative aiming to foster such collaborations in the field of family strengthening programs.

Keywords: violence-prevention and control, violence against children and adolescents, parenting, implementation science, parenting (MeSH) 


\section{INTRODUCTION}

Over a billion children experience violence each year, with a disproportionate number of those in the Global South (1). Violence against children has been linked to a multitude of immediate and long-term negative health outcomes and substantial economic costs. It violates the UN Convention on the Rights of the Child, and ending "abuse, exploitation, trafficking and all forms of violence against and torture of children" and "all forms of violence against all women and girls in the public and private spheres" are specific targets of the 2030 Sustainable Development Goals (SDG 16.2 and SDG 5.2).

There are a number of evidence-informed and promising interventions for preventing and reducing violence against children, such as those detailed in the World Health Organization-led INSPIRE framework (2-8). To achieve the SDGs, these interventions need to be scaled up and evaluated at the population level (9). However, the current evidence base on scaling up violence prevention strategies and evaluating their scale-up is limited, particularly in LMICs [see (10) on scaling social norm change interventions and (11) on scaling early childhood development].

There is a growing evidence base of research on parenting programs, including promising results in diverse LMIC settings [e.g., (12)] and studies on scaling parenting programs in highincome countries [e.g., (13)], but studies examining scaling parenting programs in LMICs are urgently needed to inform practice in the field.

While randomized trials are important for understanding intervention effectiveness, they are often conducted under circumstances that do not fully reflect real-world delivery. For instance, the external validity of study results is limited when particularly competent and well-resourced organizations take part in research studies. Thus, initially effective interventions may face a high risk of failure when taken to scale (14).

\section{CHALLENGES OF SCALE-UP}

Successful scale-up encompasses expanding program coverage and quality to larger populations or areas and embedding program delivery into lasting systems (15). The successful scale-up of violence prevention programs is challenging for a variety of reasons. As violence against children is an issue that cuts across sectors such as health, social welfare, education, and justice, violence prevention programs often require multisectoral cooperation to fit within existing service delivery systems that face substantial resource constraints. In addition to the financial commitment and material resources necessary to sustain programs, implementing agencies also need the structures and technical capacity to deliver interventions with fidelity and quality. Although task-shifting through community or lay workers is often seen as a solution for rapid scale-up of lowcost service provision in LMICs, the training, supervision, and retention of such workers can be costly and requires effective organizational management (16). Moreover, frontline service providers are frequently overburdened and underpaid, resulting in high turnover or poor service delivery in low-resource settings where the need is greatest.

We also have to accept that program implementers often resort to ad hoc and reactive adaptation-for example, to simplify or reduce costs of social interventions-thus deviating from the evidence established in randomized trials. Interventions may either mature and evolve to suit the cultural and organizational context better, or they may drift and include counterproductive changes. Substantial research has been conducted on cultural adaptation, and scholars have identified the importance of adapting interventions for implementation in routine settings. However, beyond the formal studies of adaptation, the vast majority of adaptations are ad hoc and not reported (17). There is also scarce evidence on the impact of these informal adaptations made during scaling up, highlighting a need to continue researching interventions as they are delivered more widely and within new systems. Furthermore, measuring violence is challenging, for instance due to stigma and related under-reporting $(18,19)$, and reliable administrative data on the implementation and outcomes of services related to violence against children are rarely available. Thus, continuously improving and conducting research on violence prevention programs at a large scale or within scaled-up programs presents formidable challenges.

\section{SCALE-UP OF PARENTING EVALUATION RESEARCH STUDY}

A new collaboration between researchers and implementing agencies is the Parenting for Lifelong Health Scale-Up of Parenting Evaluation Research (SUPER) study (20). This crosssectoral collaboration is working to harness implementation science in order to study and maximize the scale-up and effectiveness of parenting interventions that reduce violence against children and improve child well-being. It focuses on the recent rapid dissemination of two Parenting for Lifelong Health (PLH) parenting programs throughout LMICs, PLH for Young Children (2-9 years), and PLH for Parents and Teens (10-17 years) (21). PLH is a suite of evidence-based parent training programs based on social learning theory and designed to reduce violence against children. Originally developed based on evidence of key parenting program components $(3,22)$, and tested in South Africa, PLH programs have demonstrated positive impacts in randomized trials in reducing violence against children, improving child development and mental health, and increasing family economic well-being (23-26).

The PLH programs involve a series of weekly group meetings and/or home visits based on the structure provided by the intervention manuals. Since their initial testing, PLH for Young Children and PLH for Parents and Teens have been rapidly disseminated to over 25 LMICs at varying degrees of scale, with additional trials forthcoming in other countries. A range of government, non-governmental, and parastatal agencies deliver PLH, often within large-scale donor-driven initiatives in combination with other social services and implementation packages. For example, in several countries in Sub-Saharan 


\section{Scale-Up of Parenting Evaluation Research (SUPER) study}

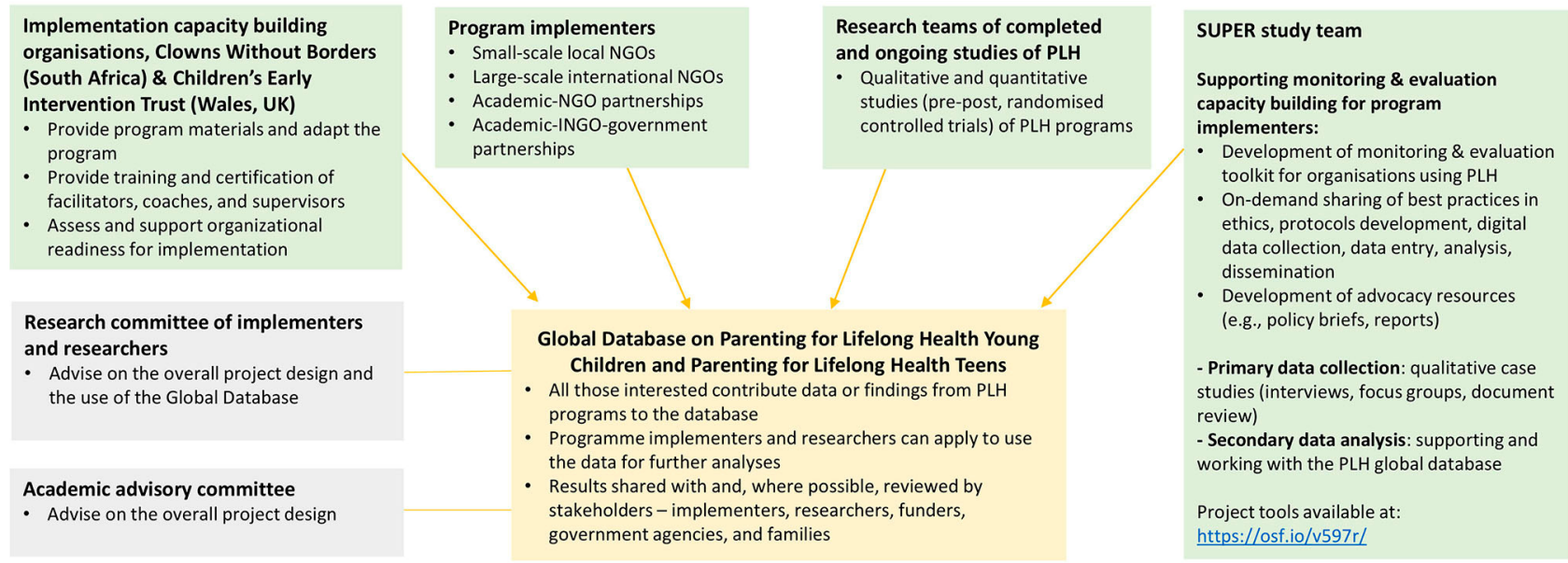

FIGURE 1 | Overview of the collaborations linked to the SUPER study.

Africa, PLH has been delivered within the DREAMS projects funded by PEPFAR-USAID focusing on adolescent girls and young women. In some settings, PLH programs have been integrated into existing government packages of services, such as the Philippines' government conditional cash transfer system and the Thailand public health promotion system (27-29). By the end of 2022, PLH programs are expected to reach approximately half a million families in Sub-Saharan Africa, Eastern Europe, South and Southeast Asia, and the Caribbean. In response to the COVID pandemic, in 2020 a set of parenting tips based on the PLH programs has been made freely available and accessed by estimated 136.1 million people through a global collaboration that includes international agencies, as well as governments and NGOs (30).

The SUPER study represents an opportunity for researchers, policymakers, donors, implementing agencies, and community stakeholders from within and outside LMICs to collaborate in order to deepen our understanding of the scale-up of family-based interventions in low-resource settings (see Figure 1 for an overview). The study aims to examine processes for effectively adopting, implementing, adapting, monitoring, and disseminating PLH programs. Translational research is a particular focus of the SUPER study, investigating processes and mechanisms for successful delivery of evidence-informed interventions through existing service delivery structures. It also examines program transferability across cultures and contexts, and how variations in design, implementation approach, and participant engagement are associated with family and programlevel outcomes. Finally, it addresses questions around financial and human resources needed to sustain scale-up and identifies overall trends and factors related to successful scale-up. Analyses of program costs may also be used to assess and improve the performance of PLH programs to maximize child well-being.
The SUPER study will use innovative research methods, drawing on ongoing service delivery data, as well as qualitative and quantitative research data collection that includes trial data, to generate quality evidence that will inform programming. The study will include data at the individual, familial, organizational, and national levels. It will focus on insights for action, andbeing mindful of the burden on service providers-aim to uphold the principle to "only collect data you can commit to use" [(31), p. 26]. Another major component of the study is mutual learning and ongoing program improvement, through which researchers gain insights about implementation at scale while implementing agencies gain skills in robust monitoring strategies and evidence generation. Collaborators will also work together to maximize the dissemination and utilization of research at community, national, and international levels. The SUPER study is thus offering a window of opportunity to close the gap between research and practice in the area of violence prevention and enhancement of child well-being through parenting support.

\section{DISCUSSION}

Achieving SDG targets 5.2 and 16.2 by ending violence against children will require researchers, technical experts, policymakers, governments, donors, implementing agencies, local program managers, and community stakeholders to work closely together to answer challenging questions regarding how programs can both be effective and sustained at scale. Through these collaborations, we may begin to learn how we can best prevent violence against children and support frontline violence prevention. As a global community, it is essential that we advance scientific knowledge on what works, for whom, and how, to improve the well-being of children and their families at scale; the PLH SUPER study aims to act on this agenda. 


\section{DATA AVAILABILITY STATEMENT}

The original contributions presented in the study are included in the article/supplementary material, further inquiries can be directed to the corresponding author. Study materials are available on the project Open Science Framework page: https:// osf.io/v597r/.

\section{AUTHOR CONTRIBUTIONS}

YS, LC, and JL have led the writing of the paper. All authors have contributed to conceptualizing the paper, reviewed the manuscript, approved the final manuscript as submitted, and agree to be accountable for all aspects of the work.

\section{FUNDING}

The PLH SUPER study has received funding from the European Research Council (ERC) under the European Union's Horizon 2020 research and innovation program (Grant Agreement No. 737476 and No. 771468), Research England, the UK Research and Innovation (UKRI) Global Challenges Research Fund (GCRF) through the UKRI GCRF Accelerating Achievement for Africa's Adolescents Hub (Grant Ref: ES/S008101/1), the Complexity and Relationships in Health Improvement Programmes of the Medical Research Council MRC UK and Chief Scientist Office (Grant: MC_UU_12017/14 and CSO SPHSUU14, MC_UU_1201711 and CSO SPHSU11), and the National Research Foundation of South Africa (Grant No. 118571), and the Oak Foundation.

\section{REFERENCES}

1. Hillis S, Mercy J, Amobi A, Kress H. Global prevalence of past-year violence against children: a systematic review and minimum estimates. Pediatrics. (2016) 137:e20154079. doi: 10.1542/peds.2015-4079

2. World Health Organization. INSPIRE: Seven Strategies for Ending Violence Against Children. Geneva (2016).

3. Leijten P, Gardner F, Melendez-Torres GJ, Van Aar J, Hutchings J, Schulz S, et al. Meta-analyses: key parenting program components for disruptive child behavior. J Am Acad Child Adolesc Psychiatry. (2019) 58:18090. doi: 10.1016/j.jaac.2018.07.900

4. Knerr W, Gardner F, Cluver LD. Improving positive parenting skills and reducing harsh and abusive parenting in low- and middle-income countries: a systematic review. Prev Sci. (2013) 14:352-63. doi: 10.1007/s11121-012-0314-1

5. Chen M, Chan KL. Effects of parenting programs on child maltreatment prevention a meta-analysis. Trauma Violence Abuse. (2016) 17:88-104. doi: 10.1177/1524838014566718

6. Vlahovicova K, Melendez-Torres GJ, Leijten P, Knerr W, Gardner F. Parenting programs for the prevention of child physical abuse recurrence: a systematic review and meta-analysis. Clin Child Fam Psychol Rev. (2017) 20:1-15. doi: 10.1007/s10567-017-0238-1

7. McCoy A, Melendez-Torres GJ, Gardner F. Parenting interventions to prevent violence against children in low- and middle-income countries in East and Southeast Asia: a systematic review and multi-level meta-analysis. Child Abuse Neglect. (2020) 103:104444. doi: 10.1016/j.chiabu.2020.104444

8. Pundir P, Saran A, White H, Subrahmanian R, Adona J. Interventions for reducing violence against children in low- and middle-income countries: an evidence and gap map. Campbell Syst Rev. (2020) 16:e1120. doi: $10.1002 / \mathrm{cl} 2.1120$

\section{ACKNOWLEDGMENTS}

The PLH SUPER study would not be possible without the support of all of the participating organizations. In addition to the co-authors and their institutions, we would like to acknowledge the input of the following contributors: Roselyn Were from Catholic Relief Services Zimbabwe; Alison Koler, John Charles, Amal Athuman, Esther Ndyetabura and Kassimu Tani from Pact Tanzania; Naftali Ng-ondi from the Tanzanian Ministry of Health, Community Development, Gender, Elderly and Children; Djeneba Coulibaly-Traore and Aline Masengo from Catholic Relief Services DRC; Egle Havrdova, Marek Havrda from Schola Empirica; Chandré Gould from the Institute for Security Studies Africa; Amalee McCoy from the University of Oxford; Laura Ruhl, Julia Songok, and Astrid Christofferson-Deb from AMPATH Kenya; Felix Monday and Seamus Regan from Catholic Relief Services South Sudan; Kaitlyn Maloney from Catholic Relief Services Headquarters; Victoria Achut from South Sudan's Ministry of Health; Bindza Ginindza and Nicole Miller from Pact Eswatini; Frederique JeanBaptiste from Catholic Relief Services Haiti; Kaaren Mathias from the Emmanuel Hospital Association; Galina Lesco from the Health for Youth Association, Chisinau, Republic of Moldova; Justus Ikemer from the Academic Model Providing Access to Healthcare (AMPATH); and Suzan Eriksson, Anna Booij, Mpume Danisa, and Nyasha Manjengenja from Clowns Without Borders South Africa. The findings and conclusions in this report are those of the authors and do not represent the official position of the Centers for Disease Control and Prevention.

9. Eisner M, Nivette A, Murray AL, Krisch M. Achieving populationlevel violence declines: implications of the international crime drop for prevention programming. J Public Health Policy. (2016) 37:6680. doi: 10.1057/s41271-016-0004-5

10. Goldmann L, Lundgren R, Welbourn A, Gillespie D, Bajenja E, Muvhango L, et al. On the CUSP: the politics and prospects of scaling social norms change programming. Sexual Reprod Health Matters. (2019) 27:5163. doi: 10.1080/26410397.2019.1599654

11. Aboud FE, Yousafzai AK, Nores M. State of the science on implementation research in early child development and future directions. Ann NY Acad Sci. (2018) 1419:264-71. doi: 10.1111/nyas.13722

12. Gardner F, Montgomery P, Knerr W. Transporting evidence-based parenting programs for child problem behavior (age 3-10) between countries: systematic review and meta-analysis. J Clin Child Adolesc Psychol. (2015) 45:74962. doi: 10.1080/15374416.2015.1015134

13. Hutchings J. Introducing, researching, and disseminating the incredible years programmes in Wales. Int J Conflict Violence. (2012) 6:225-33. doi: $10.4119 / \mathrm{ijcv}-2914$

14. Banerjee A, Banerji R, Berry J, Duflo E, Kannan H, Mukerji S, et al. From proof of concept to scalable policies: challenges and solutions, with an application. $J$ Econ Perspect. 31:73-102. doi: 10.1257/jep.31.4.73

15. World Health Organization; ExpandNet. Practical Guidance for Scaling Up Health Service Innovations. Geneva (2009). Available online at: https:// expandnet.net/PDFs/WHO_ExpandNet_Practical_Guide_published.pdf.

16. Tomlinson M, Hunt X, Rotheram-Borus MJ. Diffusing and scaling evidencebased interventions: eight lessons for early child development from the implementation of perinatal home visiting in South Africa. Ann NY Acad Sci. (2018) 1419:218-29. doi: 10.1111/nyas.13650

17. Baumann AA, Powell BJ, Kohl PL, Tabak RG, Penalba V, Proctor EK, et al. Cultural adaptation and implementation of evidence-based parent-training: 
a systematic review and critique of guiding evidence. Child Youth Serv Rev. (2015) 53:113-20. doi: 10.1016/j.childyouth.2015.03.025

18. Cerna-Turoff I, Fang Z, Meierkord A, Wu Z, Yanguela J, Bangirana CA, Meinck et al. Factors associated with violence against children in lowand middle-income countries: a systematic review and meta-regression of nationally representative data. Trauma Violence Abuse. (2021) 22:21932. doi: $10.1177 / 1524838020985532$

19. Devries K, Knight L, Petzold M, Merrill KG, Maxwell L, Williams A, et al. Who perpetrates violence against children? A systematic analysis of age-specific and sex-specific data. BMJ Paediatrics Open. (2018) 2:115. doi: 10.1136/bmjpo-2017-000180

20. Shenderovich Y, Ward CL, Lachman JM, Wessels I, Sacolo-Gwebu H, Okop $\mathrm{K}$, et al. Evaluating the dissemination and scale-up of two evidence-based parenting interventions to reduce violence against children: study protocol. Implement Sci Commun. (2020) 1:109. doi: 10.1186/s43058-020-00086-6

21. World Health Organization. Parenting for Lifelong Health: A Suite of Parenting Programmes to Prevent Violence (2020). Available online at: https://www.who.int/teams/social-determinants-of-health/parenting-forlifelong-health (accessed January 31, 2021).

22. Kaminski JW, Valle LA, Filene JH, Boyle CL. A meta-analytic review of components associated with parent training program effectiveness. $J$ Abnormal Child Psychol. (2008) 36:567-89. doi: 10.1007/s10802-007-9201-9

23. Cooper PJ, Tomlinson M, Swartz L, Landman M, Molteno C, Stein A, et al. Improving quality of mother-infant relationship and infant attachment in socioeconomically deprived community in South Africa: randomised controlled trial. BMJ. (2009) 338:1-8. doi: 10.1136/bmj.b974

24. Morgan B, Kumsta R, Fearon P, Moser D, Skeen S, Cooper P, et al. Serotonin transporter gene (SLC6A4) polymorphism and susceptibility to a homevisiting maternal-infant attachment intervention delivered by community health workers in South Africa: reanalysis of a randomized controlled trial. PLoS Med. (2017) 14:e1002237. doi: 10.1371/journal.pmed.1002237

25. Ward CL, Wessels IM, Lachman JM, Hutchings J, Cluver L, Kassanjee R, et al. Parenting for lifelong health for young children: a randomized controlled trial of a parenting program in South Africa to prevent harsh parenting and child conduct problems. J Child Psychol Psychiatry Allied Discipl. (2020) 61:503-12. doi: 10.1111/jcpp.13129

26. Cluver LD, Meinck F, Steinert JI, Shenderovich Y, Doubt J, Romero RH, et al. Parenting for lifelong health: a pragmatic cluster randomised controlled trial of a non-commercialised parenting programme for adolescents and their families in South Africa. BMJ Global Health. (2018) 3:116. doi: 10.1136/bmjgh-2017-000539

27. Alampay L, Lachman J, Landoy B, Madrid B, Ward C, Hutchings J, et al. Preventing child maltreatment in low- and middle-income countries: Parenting for Lifelong Health in the Philippines. In: Verma S, Petersen A, editors. Developmental Science and Sustainable Development Goals for Children and Youth. Social Indicators Research Series, Vol. 74. Springer (2018). p. 277-93. doi: 10.1007/978-3-319-96592-5_15

28. Mamauag BL, Alampay LP, Lachman JM, Madrid BJ, Hutchings J, Ward CL, et al. A south-to-south cultural adaptation of an evidencebased parenting program for families in the Philippines. Family Process. (2021). doi: 10.1111/famp.12625. [Epub ahead of print].
29. McCoy A, Lachman J, Ward C, Tapanya S, Kelly J, Mukaka M, et al. Assessing the potential for reducing violence against young children through an adapted parenting program embedded within the public health system: findings from a pre-post trial in Thailand. Res. Square [Preprint]. (2021). doi: $10.21203 /$ rs.3.rs-115234/v1

30. Cluver L, Lachman JM, Sherr L, Wessels I, Krug E, Rakotomalala S, et al. Parenting in a time of COVID-19. Lancet. (2020) 395:e64. doi: 10.1016/S0140-6736(20)30736-4

31. Gugerty M, Karlan D. The Goldilocks Challenge: Right-Fit Evidence for the Social Sector. Oxford: Oxford University Press (2018).

Conflict of Interest: LC, CW, JL, JH, and FG were involved in the development of the PLH programs. YS, JL, and IW worked on the PLH trials in South Africa and based their doctoral work on these. RJ and MM's current master's work is based on PLH. The work of LC, YS, IW, CW, JL, FG, and SB is partly funded by the UKRI GCRF Accelerating Achievement for Africa's Adolescents Hub. The work of JL and MM has been supported by a GCRF Center Hub Grant. The work of LC, YS, IW, CW, JL, FG, HF, ABab, MR, NH, and RJ has been partly funded by grants under the European Research Council's Horizon 2020 program. The work of JL, CW, and FG has also been funded by UNICEF Thailand, and the work of JH, LA, JL, CW, and FG by UNICEF Philippines. Further, JL is the former Executive Director and receives income as a current Senior Advisor and PLH Trainer at Clowns Without Borders South Africa (a non-profit organization responsible for PLH implementation). LN is Co-Director of Clowns Without Borders South Africa. CW reports grants from the National Research Foundation of South Africa and the World Childhood Foundation. RJ reports a grant from the University of Cape Town during the conduct of the study. Outside the submitted work, SB reports income from IntraHealth Inc. ABut is the co-chair of the INSPIRE: Seven strategies for ending violence against children technical package implementation working group and is a lead author of the package. $\mathrm{NH}$ reports involvement in two other parenting programs-Triple $\mathrm{P}$ and Parent-Child Interaction Therapy. JH receives occasional income as a PLH Trainer. Outside the submitted work, JM's organization, Schola Empirica, receives grants from the European Social Fund. Further, JM receives income from these grants in his role as program evaluator.

The remaining authors declare that the research was conducted in the absence of any commercial or financial relationships that could be construed as a potential conflict of interest.

Copyright (®) 2021 Shenderovich, Lachman, Ward, Wessels, Gardner, Tomlinson, Oliver, Janowski, Martin, Okop, Sacolo-Gwebu, Ngcobo, Fang, Alampay, Baban, Baumann, de Barros, Bojo, Butchart, Dippenaar, Exavery, Fang, Ferdinandi, Foran, Heinrichs, Hutchings, Kisyombe, Massetti, Mazak, Mbuyi, Singh, Polsky, Rakotomalala, Raleva, Savo and Cluver. This is an open-access article distributed under the terms of the Creative Commons Attribution License (CC BY). The use, distribution or reproduction in other forums is permitted, provided the original author(s) and the copyright owner(s) are credited and that the original publication in this journal is cited, in accordance with accepted academic practice. No use, distribution or reproduction is permitted which does not comply with these terms. 